FSM IIImî Araştırmalar Insan ve Toplum Bilimleri Dergisi 


\title{
Dünya Bankası ve Mali Kriz Üzerindeki Etkisi
}

\section{Öz}

Dünya Bankası, imar, kalkınma ve yardımlaşma alanında faaliyet gösteren uluslararası mali bir kurumdur. Üye ortakları ve müşterileri bağımsız hükümetlerden oluşur. Küreselleşmeyi sağlamanın en önemli aracı olması itibariyle, Dünya Bankasının kuruluş felsefesi, kapitalizm ve onun esaslarına dayanan küreselleşmenin fikri temelleriyle paralellik gösterir. Araştırmacıya göre uluslararası mali krizlerin Dünya Bankasıyla direkt olarak bir ilişkisi bulunmamaktadır. Ancak Dünya Bankasının küresel ekonomideki rolüne dair verileri inceleme yoluyla araştırmacı, bu kurumun mali krizlerin oluşumunda dolaylı etkileri olduğu düşüncesine varmıştır.

Anahtar Kelimeler: Dünya Bankası, mali kriz, küreselleşme.

\section{International Bank and Its Effect to Financial Crisis}

\begin{abstract}
International Bank for Reconstruction and Development, global financial institution global, shareholders and traders with a sovereign government, it is clear that the intellectual assets of the idea of the World Bank are the same intellectual assets for Globalization - as the World Bank one of the most important organs. Globalization - derived primarily from capital and the bases of the.

The researcher did not find possible be described to proceed with the World Bank to happen related to the financial crisis, but the researcher during his induction to the World Bank's role in the global economy, not luck that there are indirect links to these institutions in contributing to the financial crisis.
\end{abstract}

Keywords: International Bank, financial crisis, globalization. 


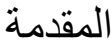

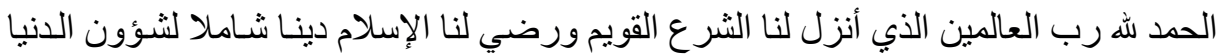

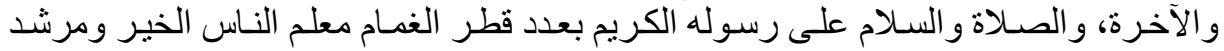

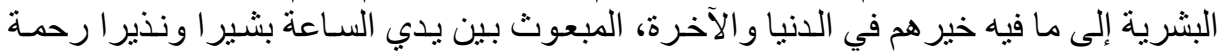

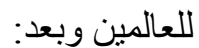

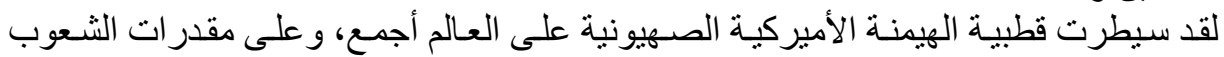

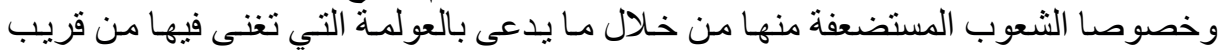
القاصي و الداني .

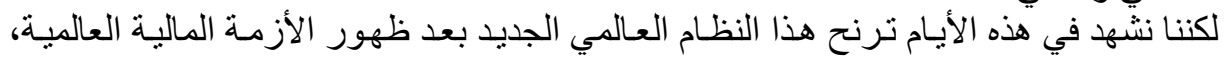

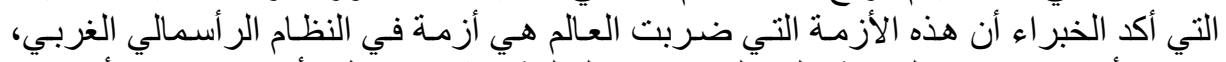

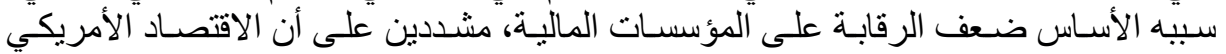

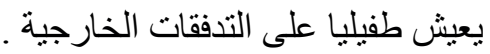

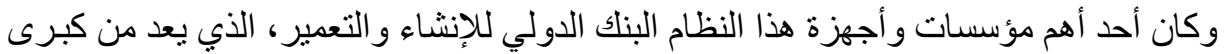

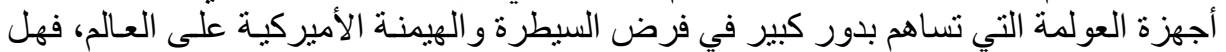

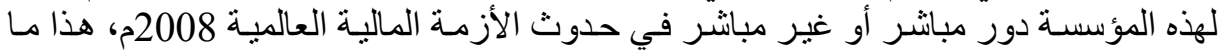

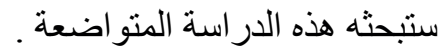
مشكلة الدر اسة و أهمينها و أهدافها:

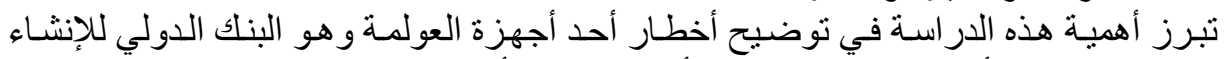

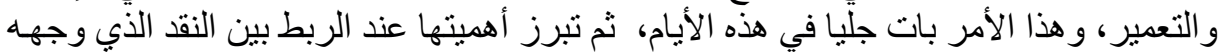

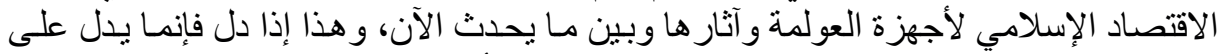

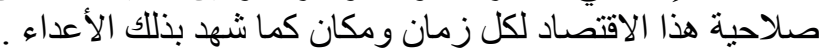
وتتمثل أهمية هذه الدر اسة من خلال الإجابة على الإنى الأسئلة التالية:

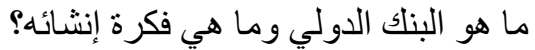

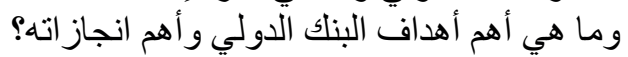
ما هي علاقة البنك الدولي بحدوث الأزمة الأل المالية الحالية الحالية؟ ما هو الحل الأمثل لعلاج مثل هذه الأزمات الاتب؟

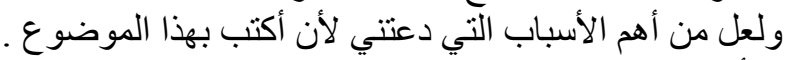

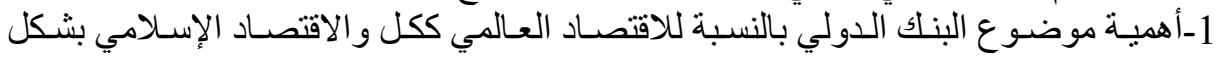

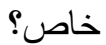
2-انشـال بـال كثير من النـاس في هذه الأيسام بموضوع الأزمـة الماليـة و أسبابها وآثار هـا

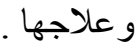
3-رغبة الباحث في إضافة مساهمة منو اضعة في توصيف الأزمـة ودور الاقتصـاد الإسـامي

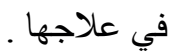
4-ربط النظرية بالتطبيق بالربط بين أجهزة العولمة و آثار ها والأزمة و أسبابها. 


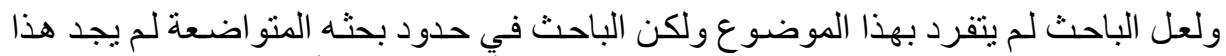

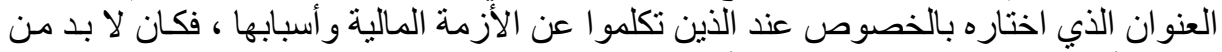

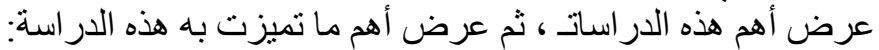

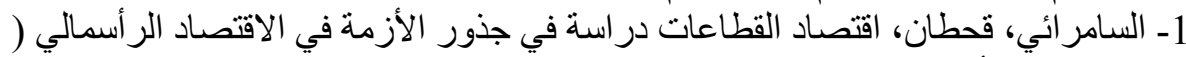

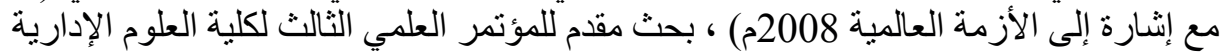

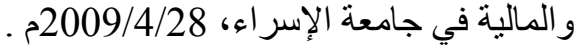

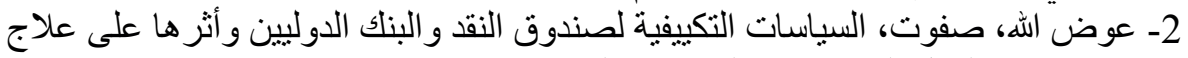

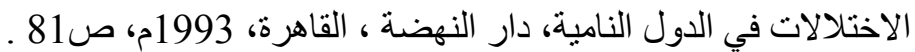

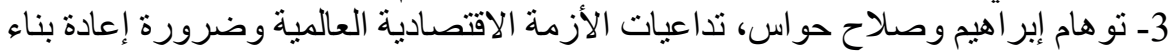

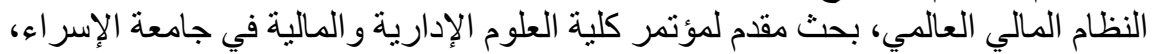
2009/4/28

حيث تطرق الباحثون إلى تحليل الأزمـة المالية العالمية و أسبابها، وتكلموا عن دور مؤسسـات

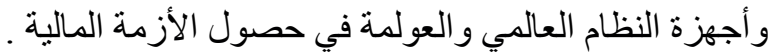

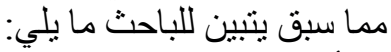

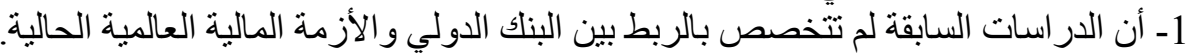

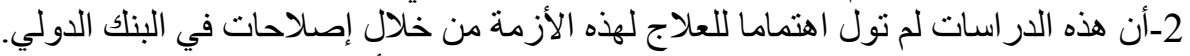

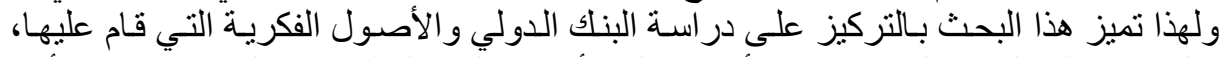

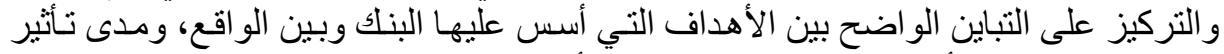

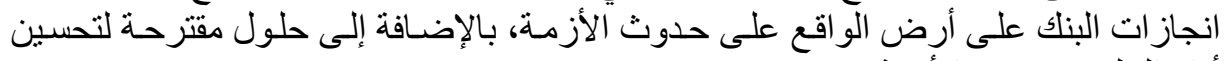

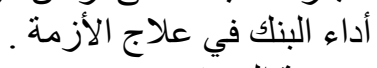

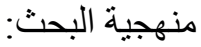

تقوم منهجية هذا البحث على المنهج الاستقر ائي والتحليلي، وجمع المعلومـات من مصسادر ها،

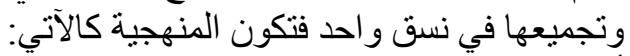

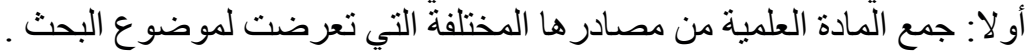

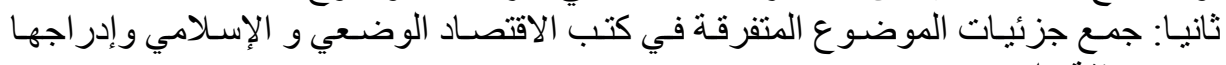

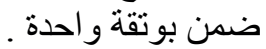
ثالثا: جمع الوقائع التطبيقية المعاصرة من مظانها في مر اكز الدراسات ووسائل الإعلام المرئية

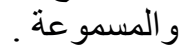

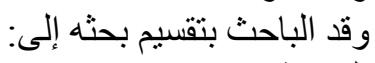
المقدمة المبان

المبحث الأول: تعريف بالبنك الدولي وفكرة نشأتها.

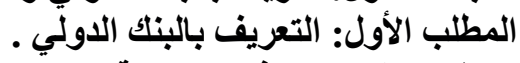

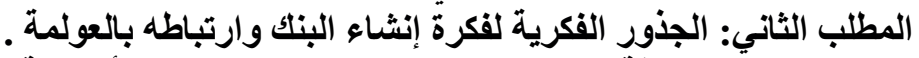

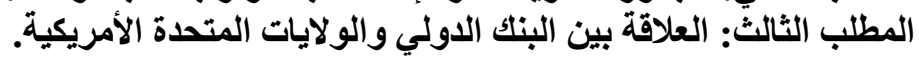

المبحث الثاني: أثر البنك الدولي على حدوث الأزمة العالمية. 


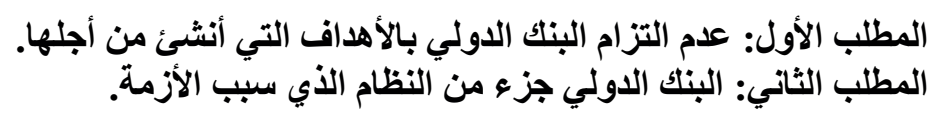

المبحث الثالث: الحلول المقترحة المتعلقة بالبنك الدولي للخروج من الأزمة المالية .

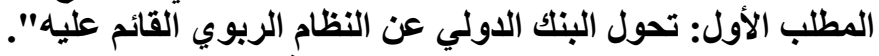

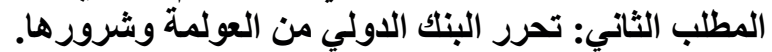

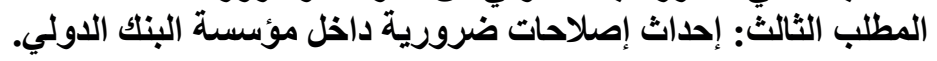
الخاتمة: التوصيات والنتائج 


\section{المبحث الأول: تعريف بالبنك الدولي وفكرة نشأته :

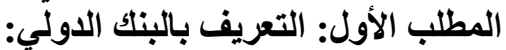

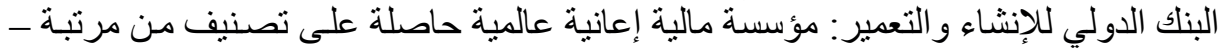

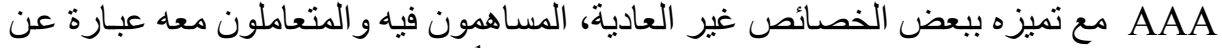

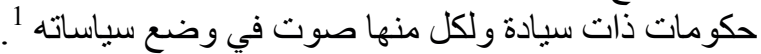

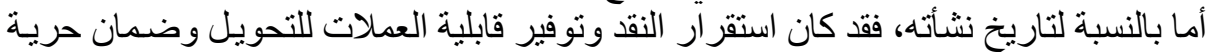

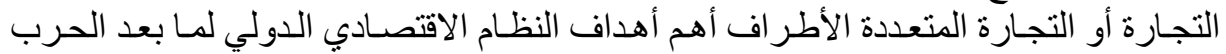

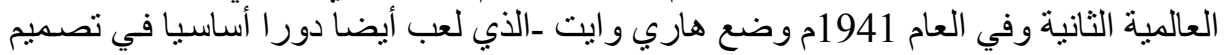

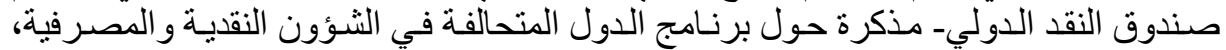

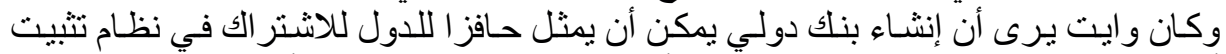

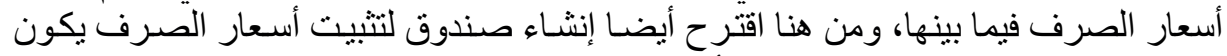

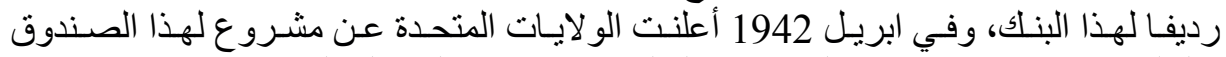

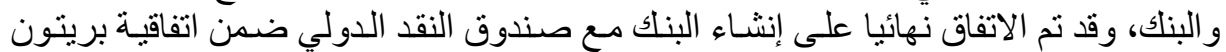

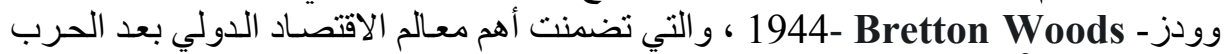

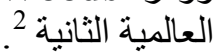

أنشئ البنك وفقا لما تقدم باسم" البنك الدولي للإنشاء و التعمير " International" Bank For

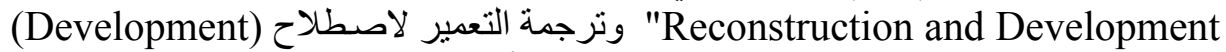

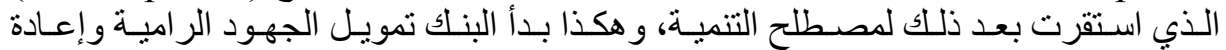

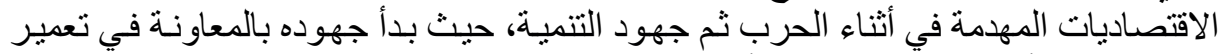

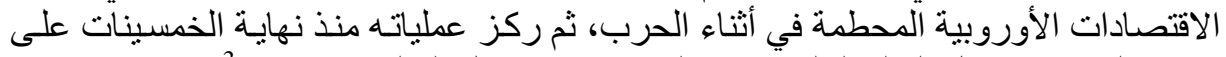

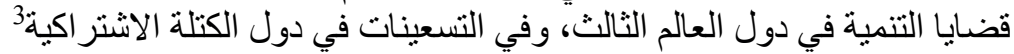

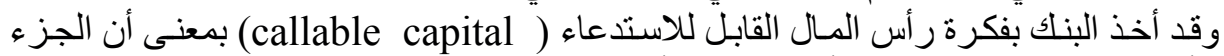

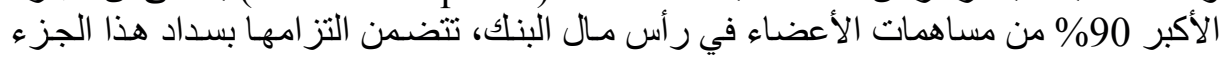

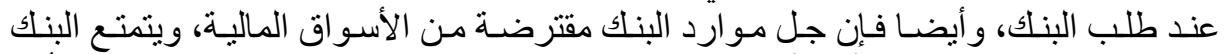

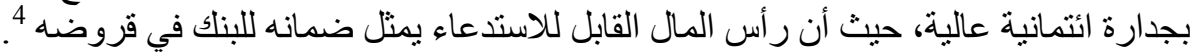

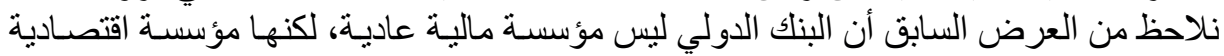

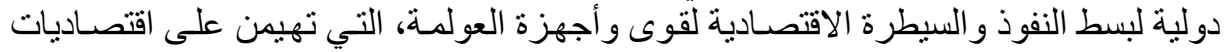

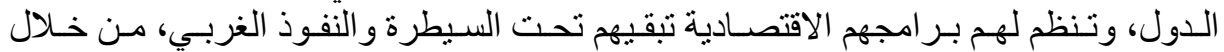

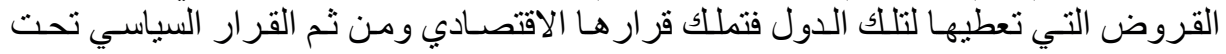
عباءات بر امج التنمية و الإصلاح الاقتصادي.

1 ـ التقرير السنوي للبنك الدولي 2008م، الثؤون الخارجية في البنك الدولي، واشنطن الو لايات المتحدة،

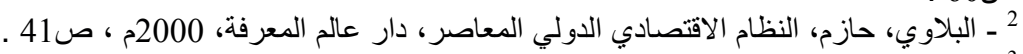

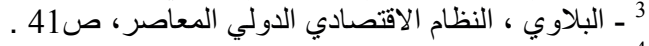


المطلب الثاني: الجذور الفكرية لفكرة إنشاء البنك وارتباطها بالعولمة:

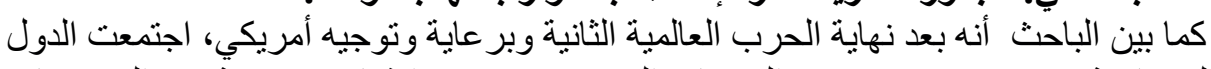

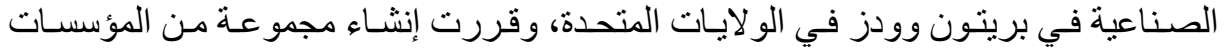

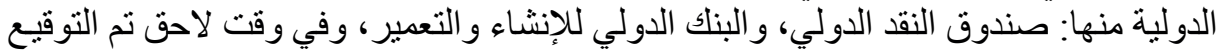

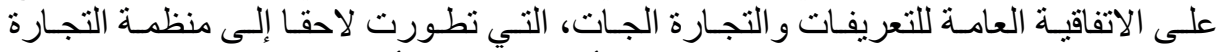

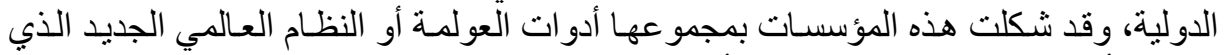

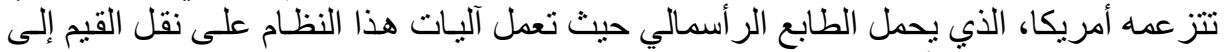

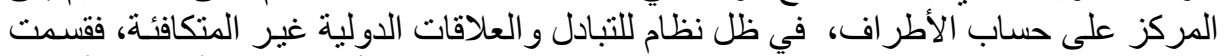

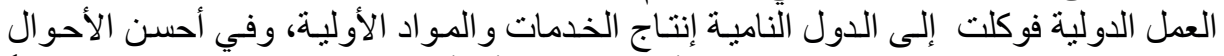

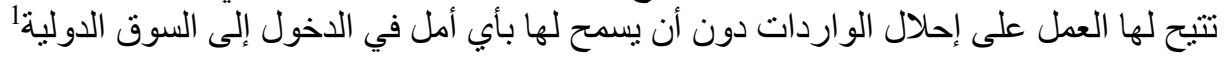

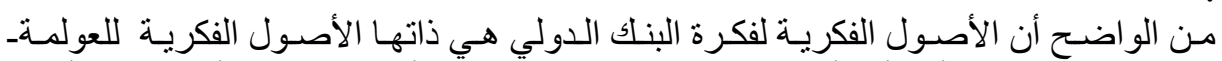

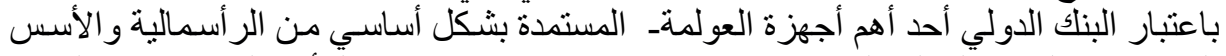

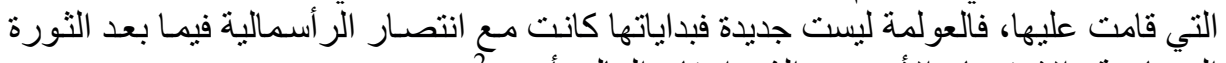

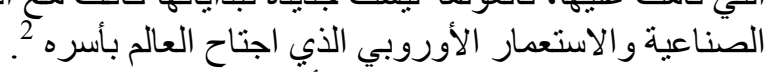

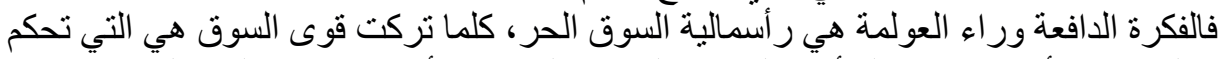

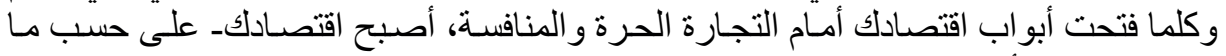

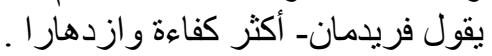

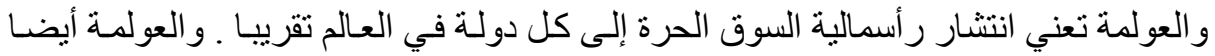

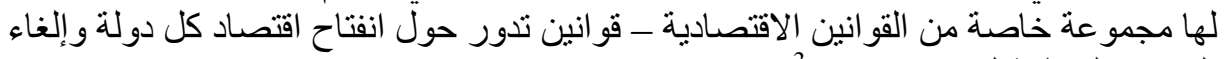

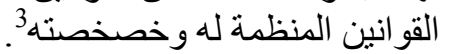

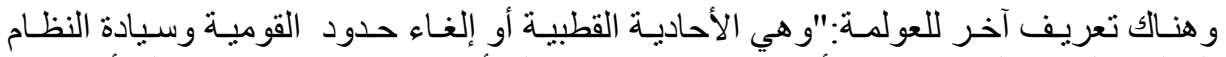

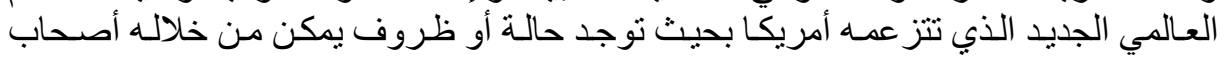

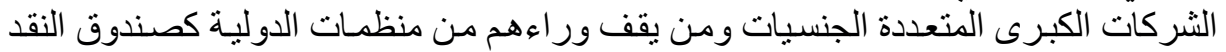

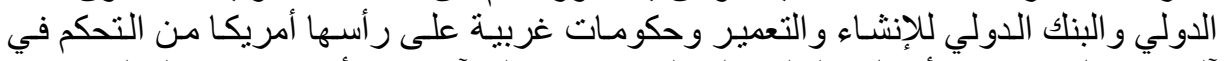

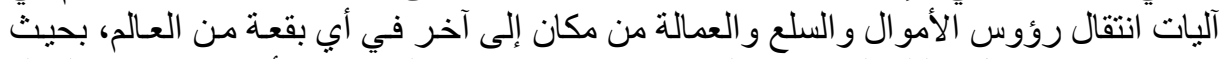

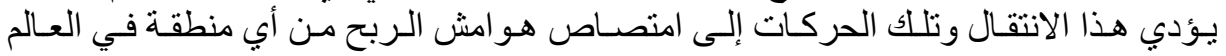

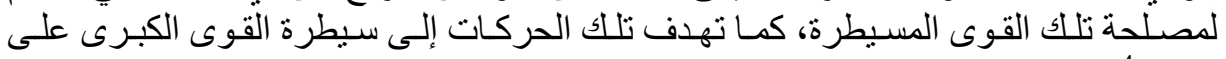

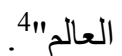

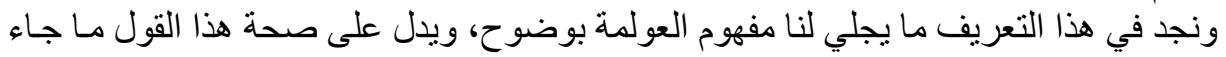

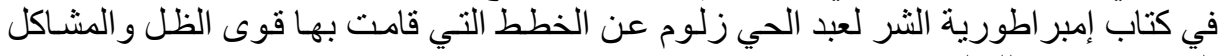

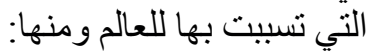

1 ـ ـ السبهاني، عبد الجبار - الوجيز في الفكر الوضعي و الإسلامي،دار وائل،عمان، ط1-2001م - ص202 ـ

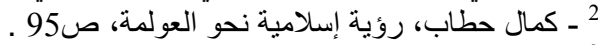

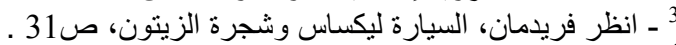

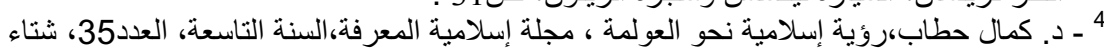


"بعد الذي حدث للاتحاد السوفيتي من انهيار ومع التقدم العلمي الهائل في تقنيات الكمبيوتر

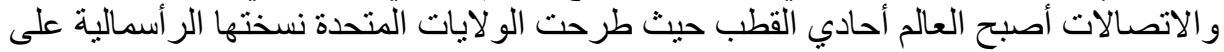

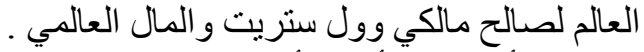

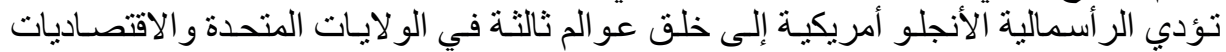

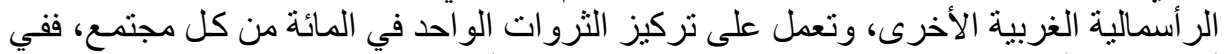

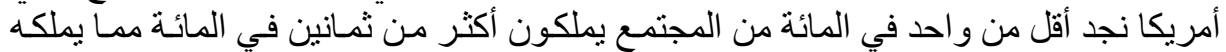

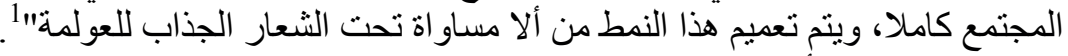

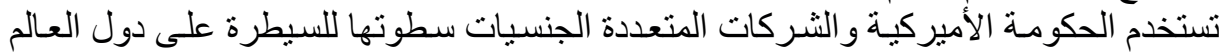

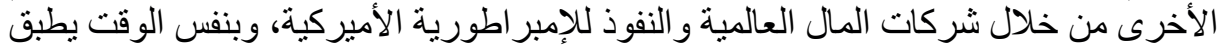

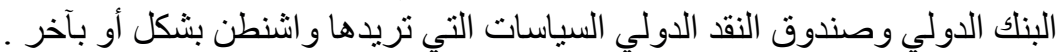

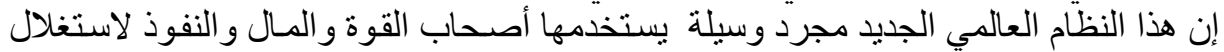
شعوب بأكملها بغض النض النظر عن الحدود الإقليمية.2.

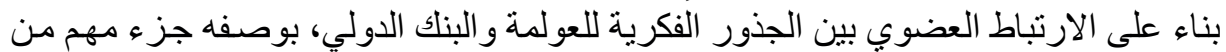

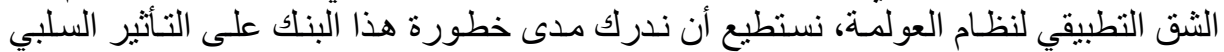

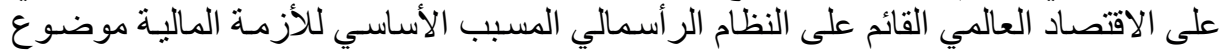

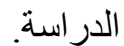

المطلب الثالث: العلاقة بين البتك الدولي والولايات المتحدة الأمريكية:

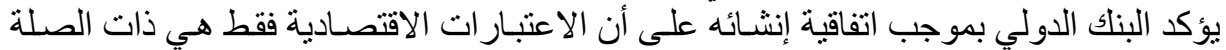

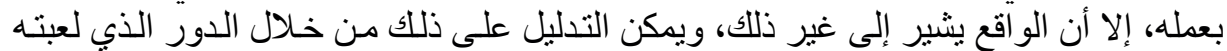

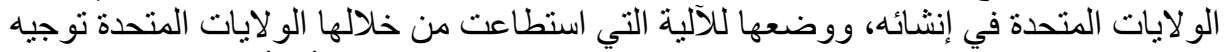

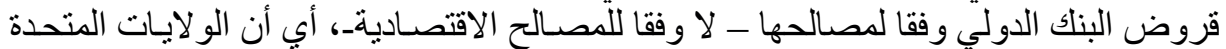

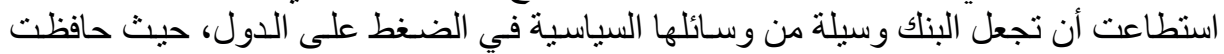

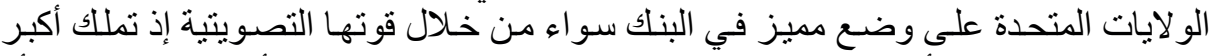

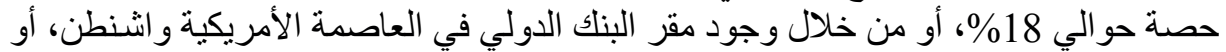

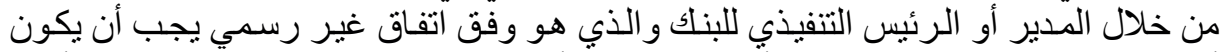

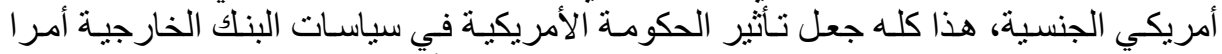

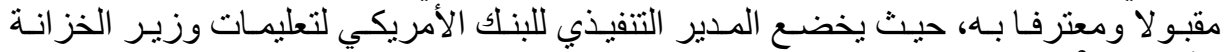

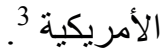

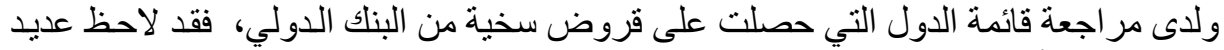

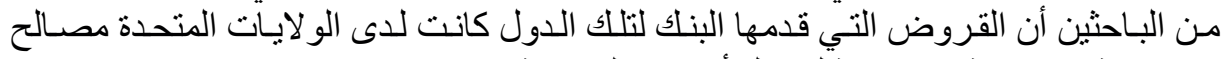

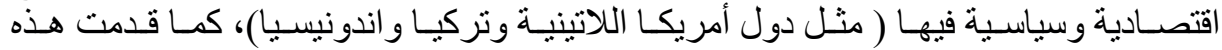

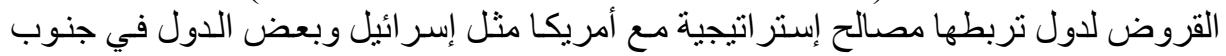

$$
\begin{aligned}
& \text { 2 } 1 \text { - زلوم، عبد الحي، إمبر اطورية الثر ، ص60 . }
\end{aligned}
$$

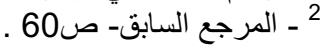

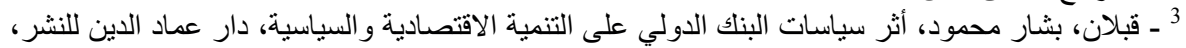

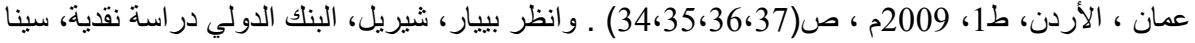




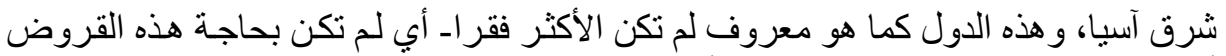

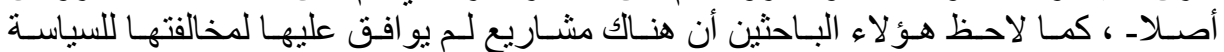

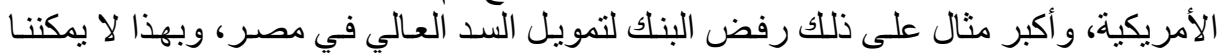

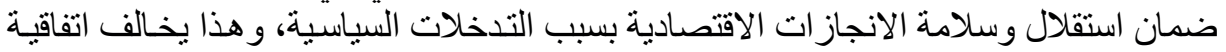

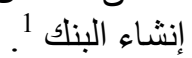
وحاليا تخضع ممارسات البنلك اليومية إلى حد بعيد لمبدأ مركب ذي جذور غير مصرفية، وهو وهو

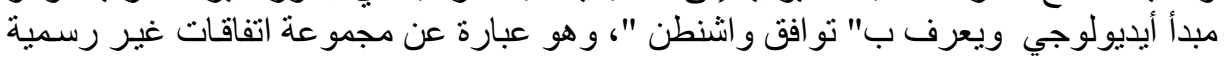

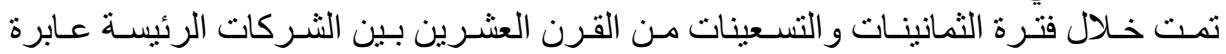

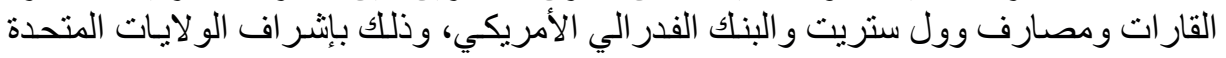

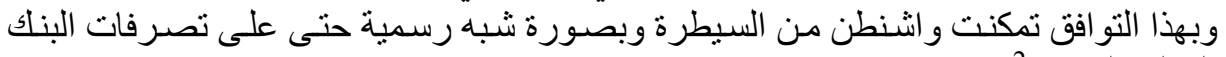
الدولي اليومية الئية ومن هنا نلحظ ارتباط آخر قد يربط بين البنك الدولي والأزمة المالية، من خلال معرفتنا لعلاقة

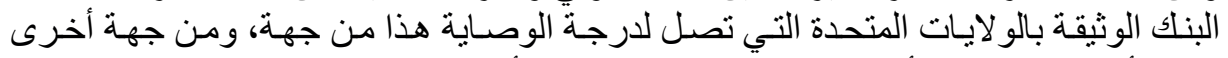

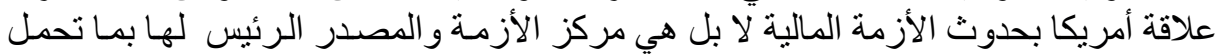

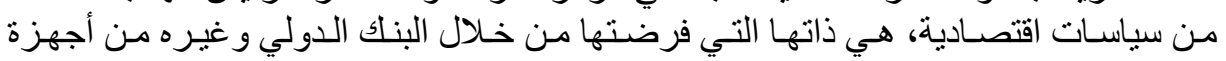
العولمة. من منية.

1 ـ ـ قبلان ، أثر سياسات البنك الدولي على التنمية الاقتصادية والسياسية، ص 37.

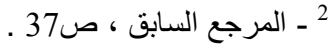


المبحث الثاني: أثثر البنك الاولي على حدوث الأزمة العالمية:

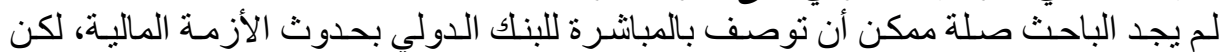

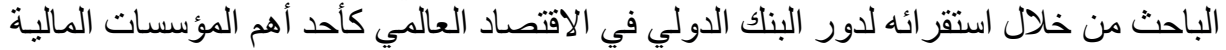

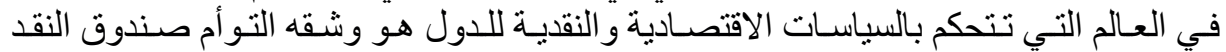

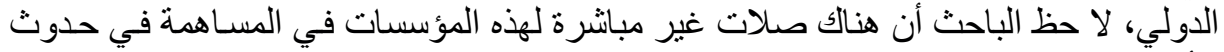

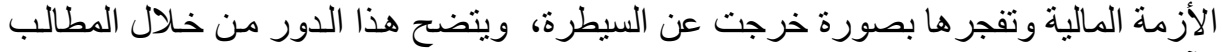

المطلب الأول: عدم التزام البنك الدولي بالأهداف التي أنشئ من أجلها:

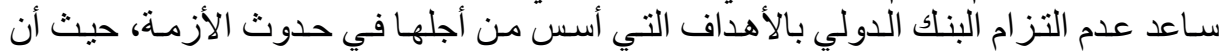

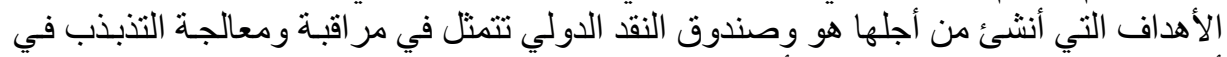

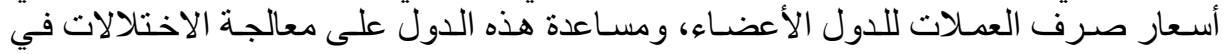

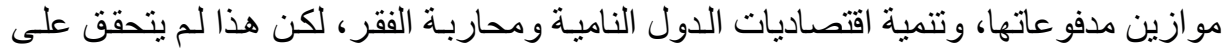

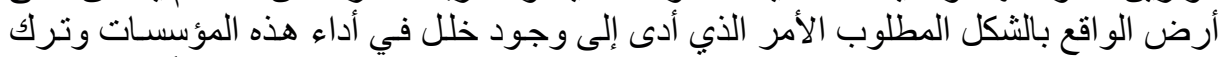

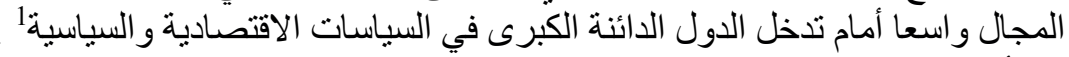

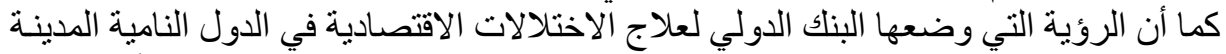

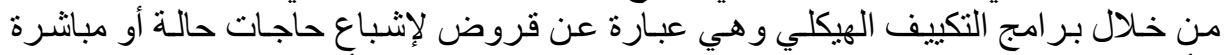

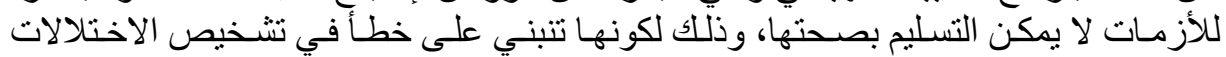

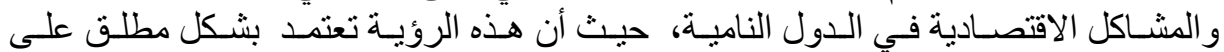

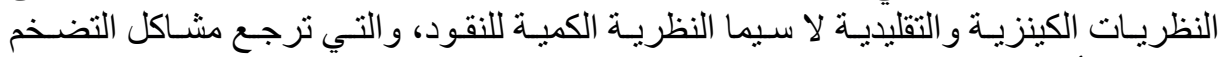

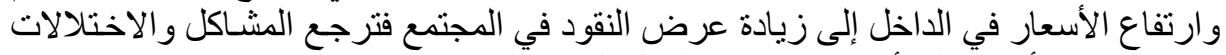

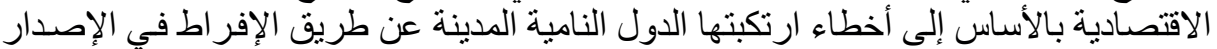

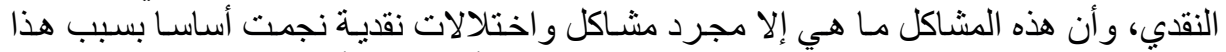

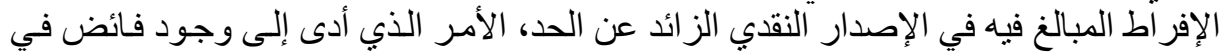

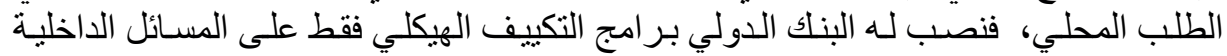

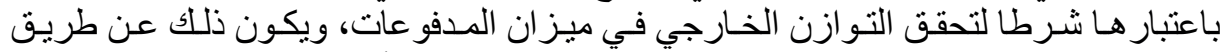

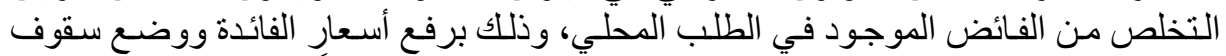

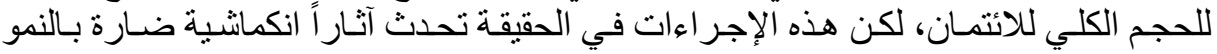

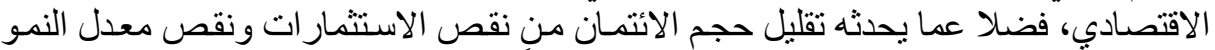

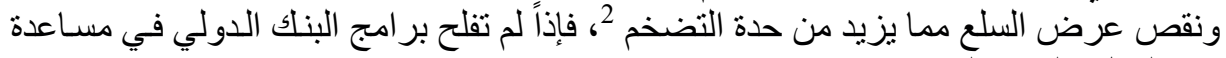

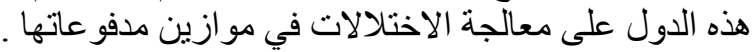

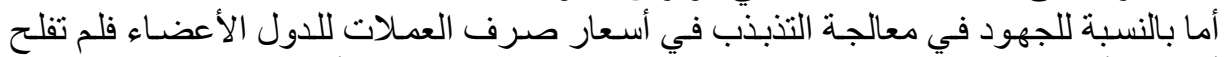

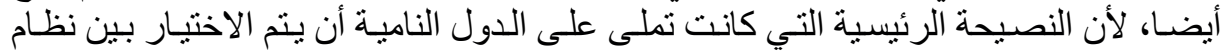

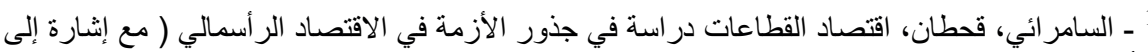
الأزمة العالمية 2008م) ، بحثث مقدم للمؤتمر العلمي الثالث لكلية العلوم الإدارية والمالية فلية في جامعة الإسراء، . 2009/4/28 2 ـ عوض الله، صفوت، السياسات التكييفية لصندوق النقد و البنك الدوليين و أثر ها على علاج الاختلالات في

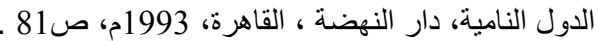




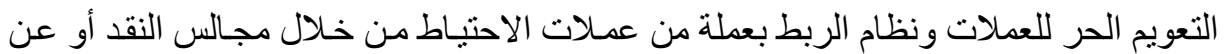

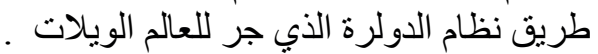

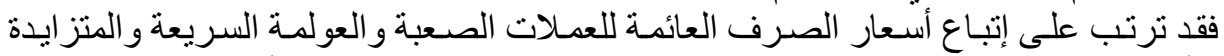

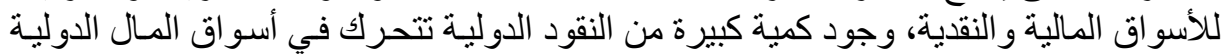
باستقلالية كاملة عن عمليات تمويل النفيلة التبادل التجاري.

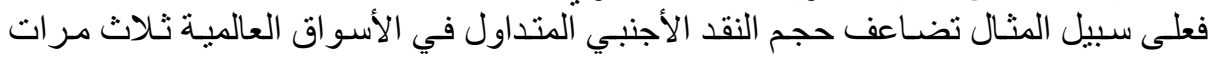

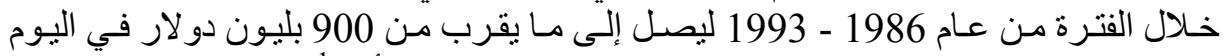

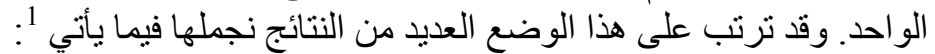

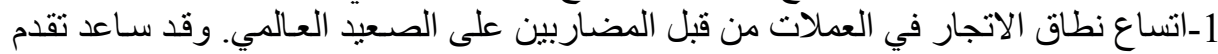

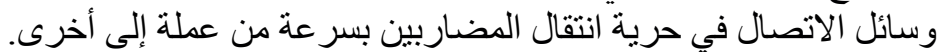

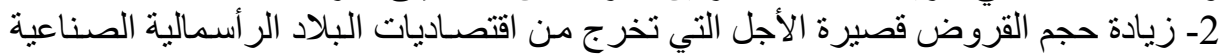

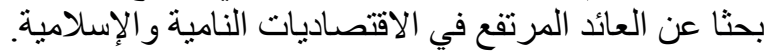

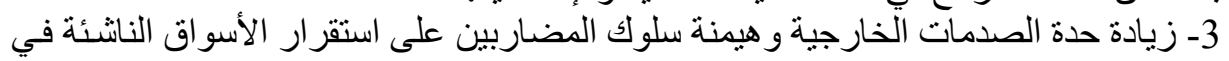

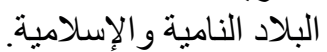
4-فثل صندوق النقد الدولي و البنك الدولي في تحقيق الاستقرار النقدي و المسالي على المستوى

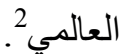

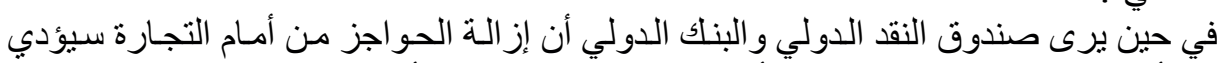

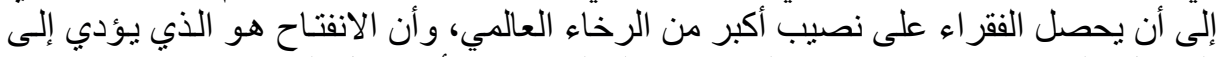

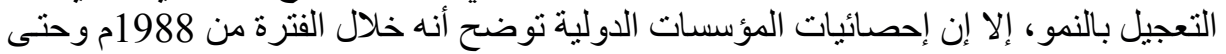

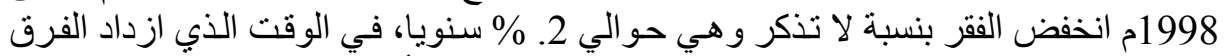

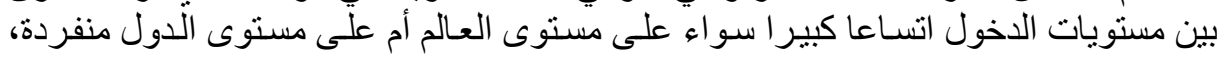

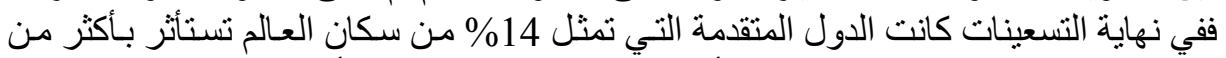

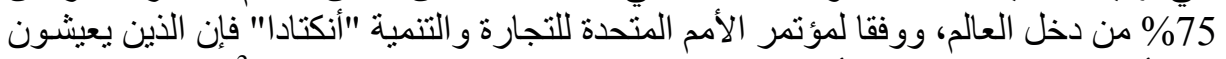

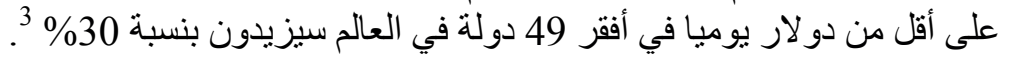

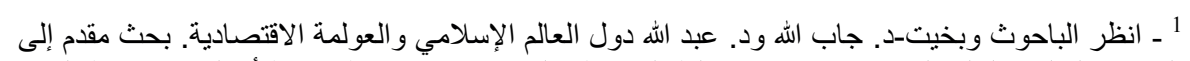

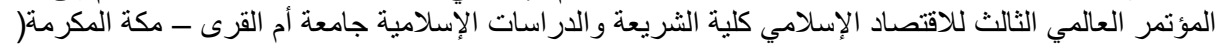

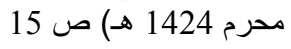

2 ـ انظر الباحوث وبخيت، دول العالم الإسلامي والعولمة الاقتصادية. ص 15

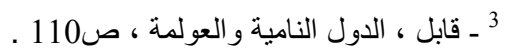


وتجدر الإشـارة إلى أن أزمـة الأسـواق المالية الآسيوية التي حدثت في عام 1997

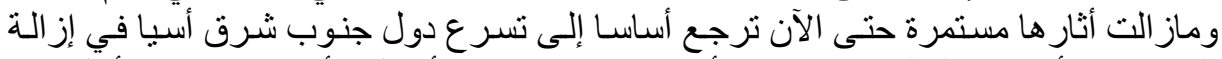

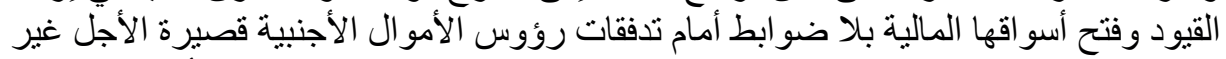

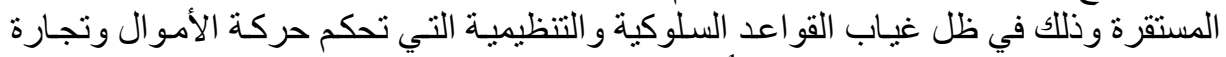

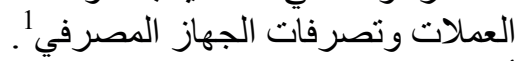

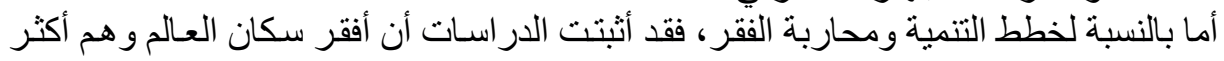

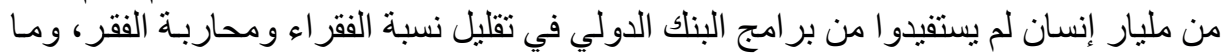

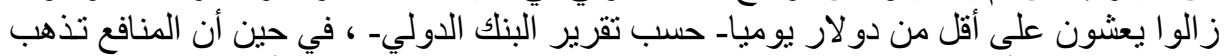

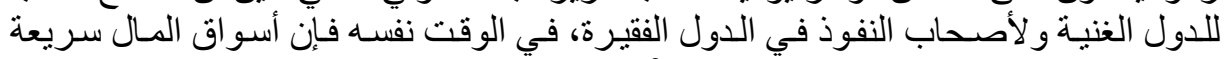

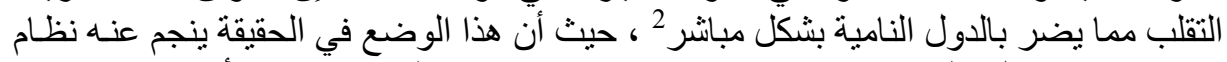

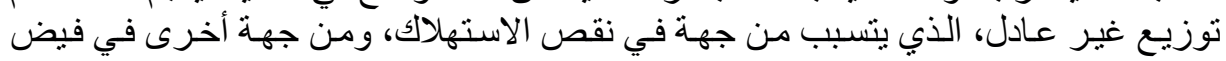

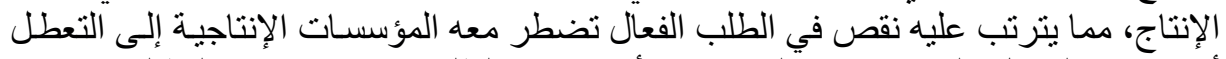

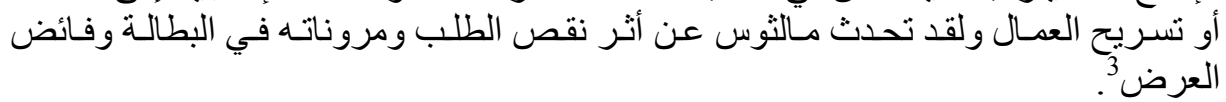

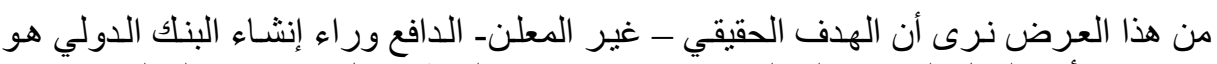

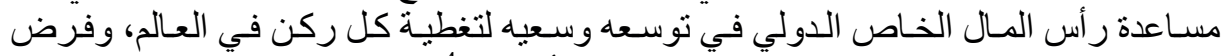

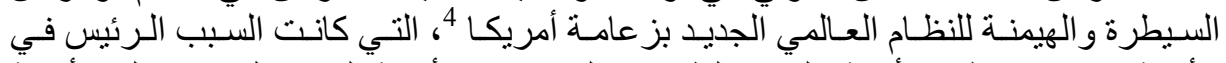

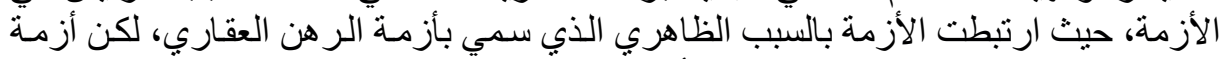

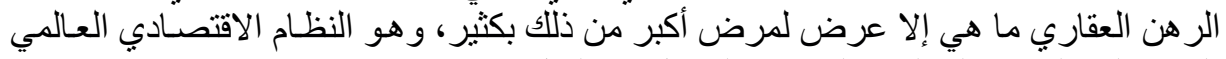

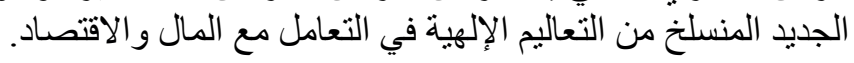

\section{المطلب الثاني: البنك الدولي جزء من النظام الذي سبب الأزمة:}

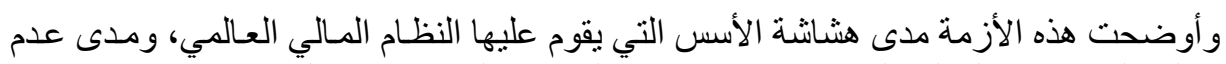

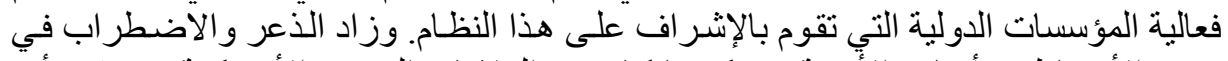

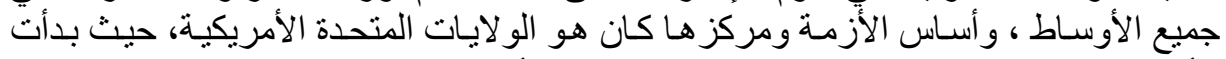

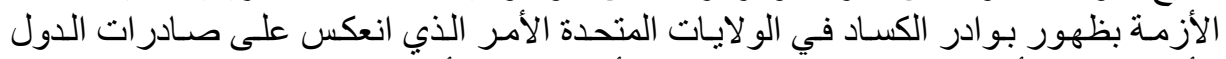

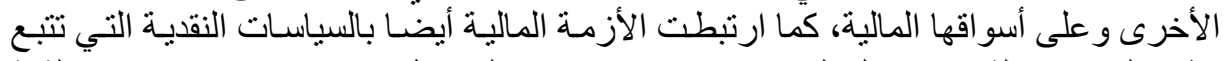

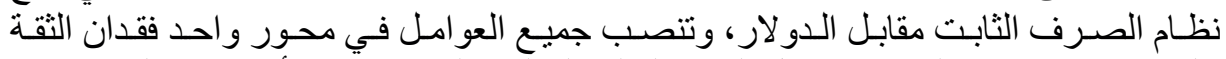

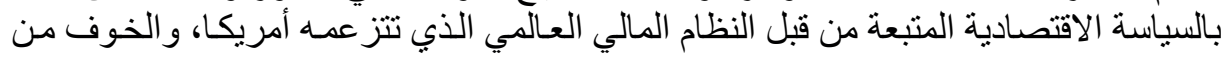

1 ـ ـ انظر الباحوث وبخيت،دول العالم الإسلامي و العولمة الاقتصادية.

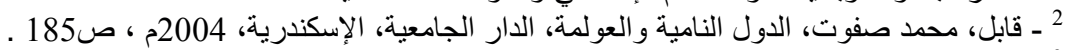

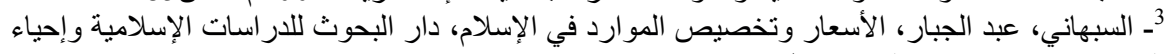

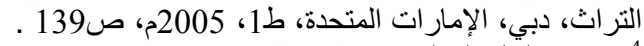

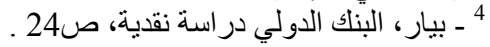




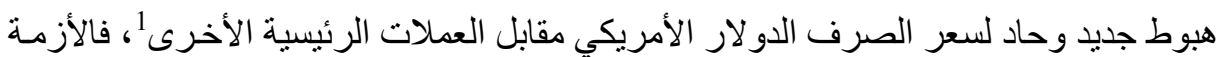

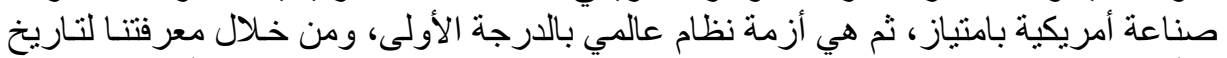

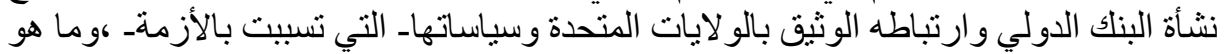

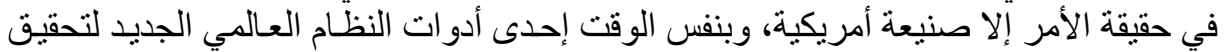

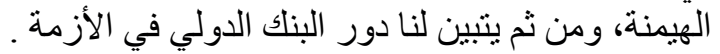

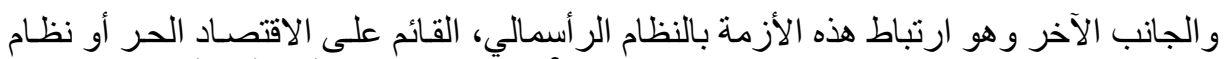

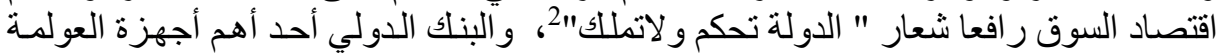

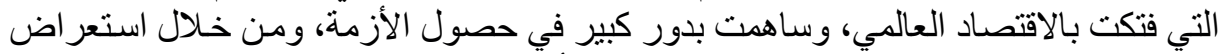

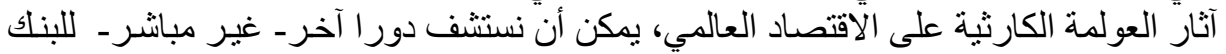
الدولي في الأزمة المالية الحالية . الألئ.

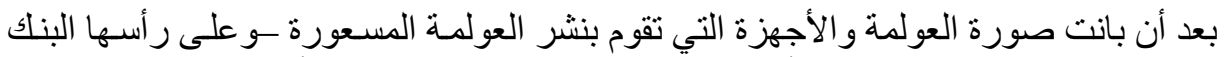

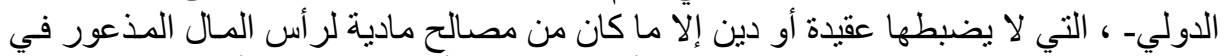

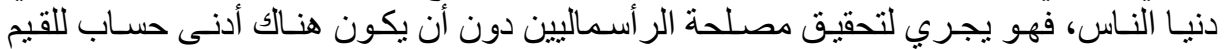
و والضو ابط الأخلاقية . فئري

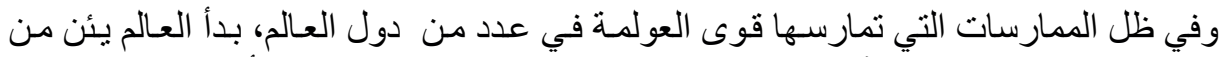

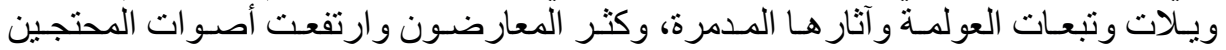

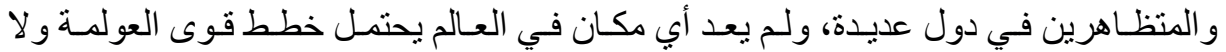

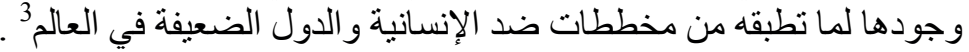

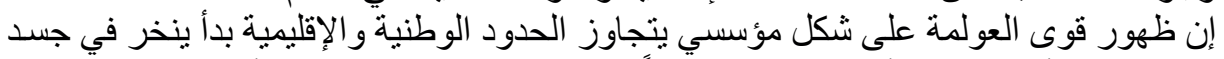

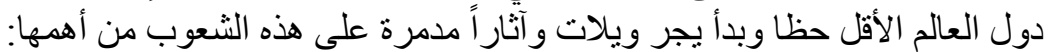

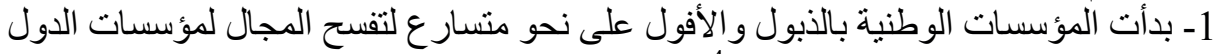

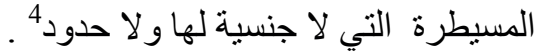

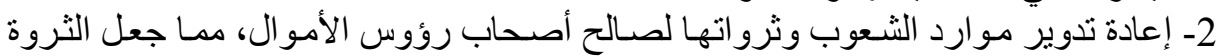

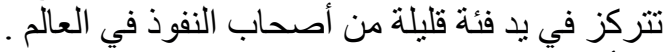

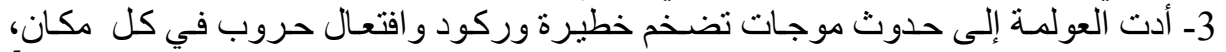

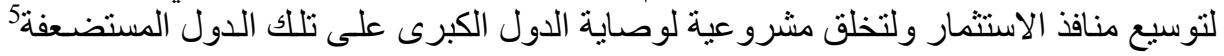

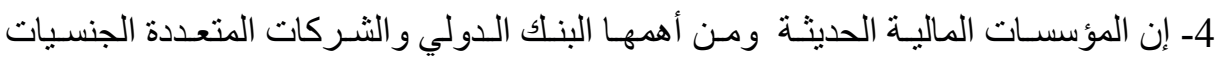

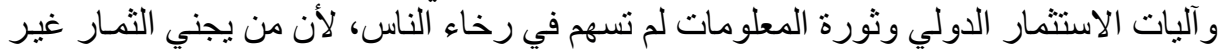

1 ـ تو هام إبر اهيم وصلاح حواس، تداعيات الأزمة الاقتصادية العالمية وضرورة إعادة بناء النظام المالي

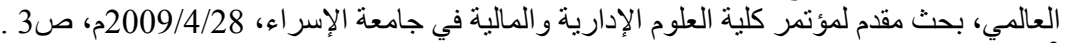

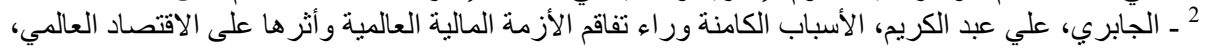

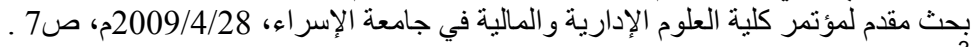

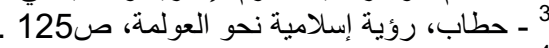

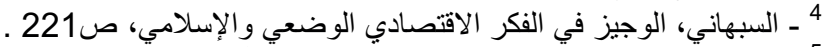

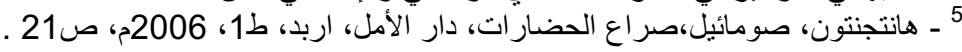




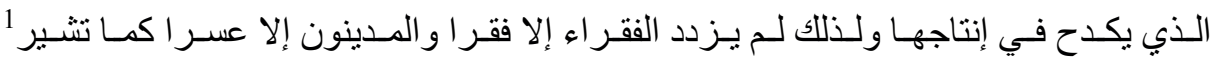

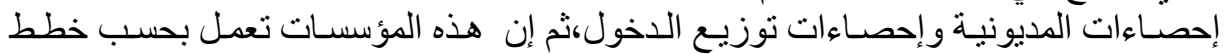

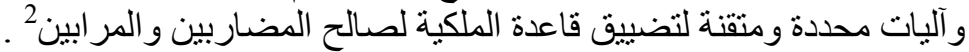

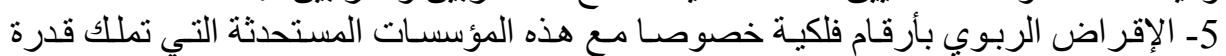

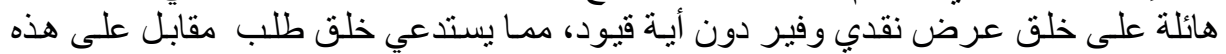

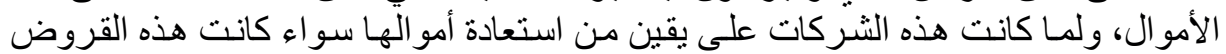

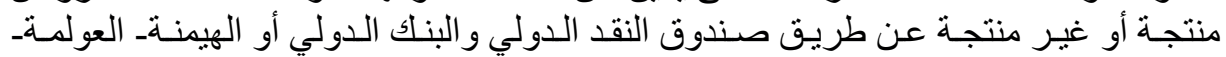

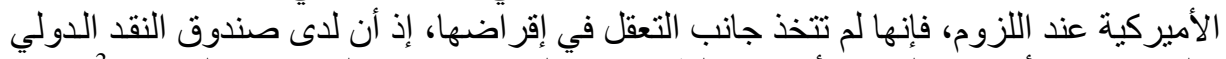

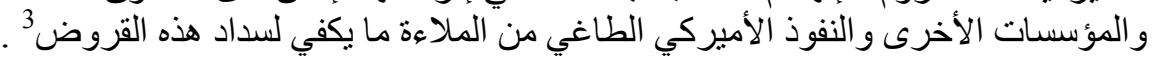

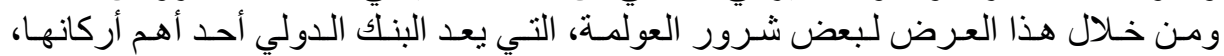

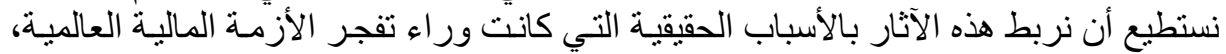

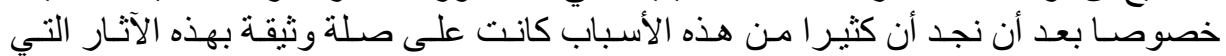

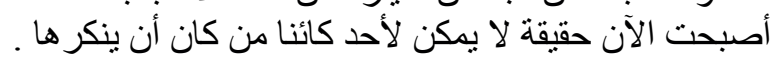

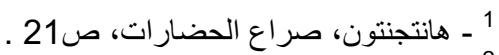

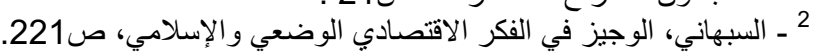
3 ـ زلوم،عبد الحي، نذر العولمة، دار الفارس، عمان، الأردن، ط1999،1 121 ، ص225 . 


\section{المبحث الثالث: الحلول المقترحة المتعلقة بالبنك الدولي للخروج من الأزمة المالية:}

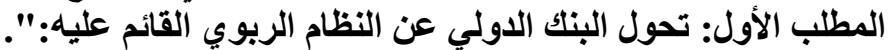

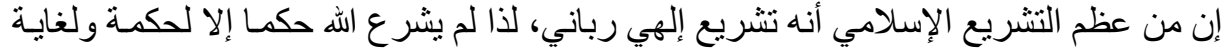

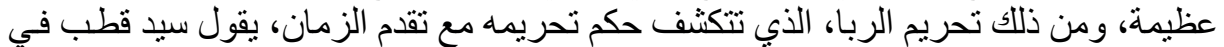

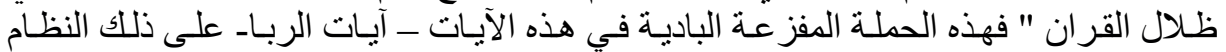

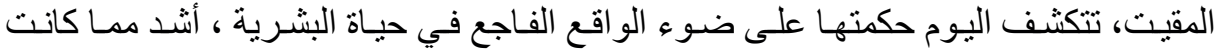

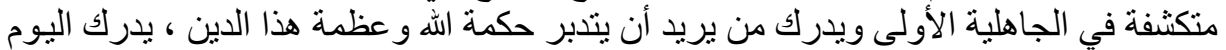

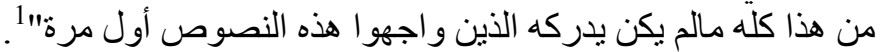

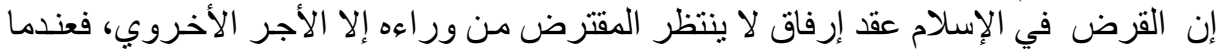

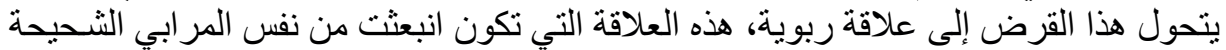

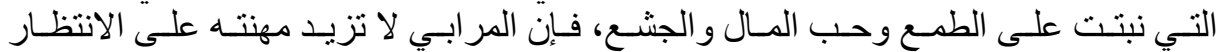

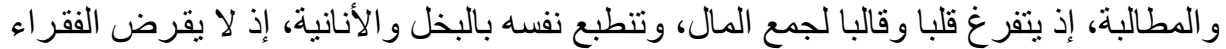

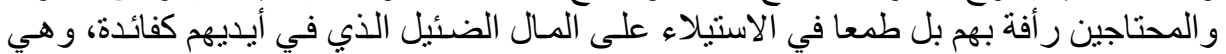

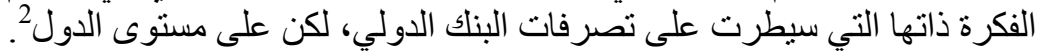

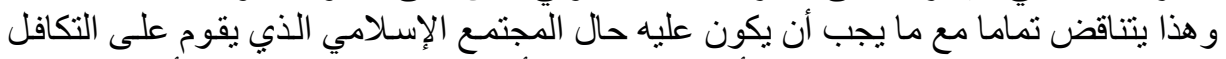

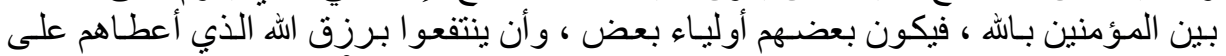

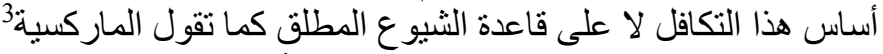

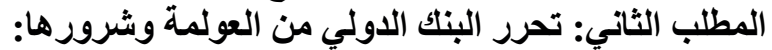

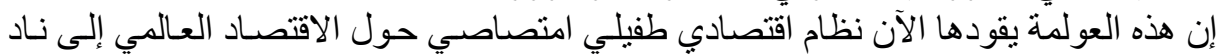

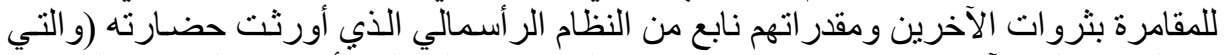

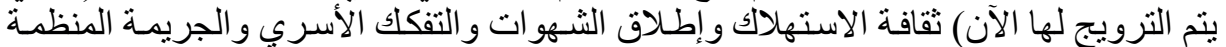

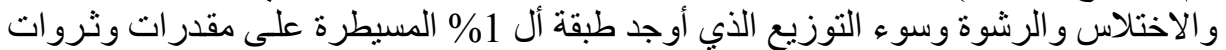

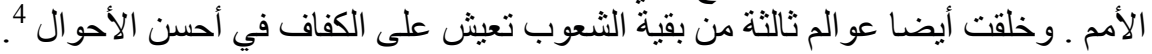

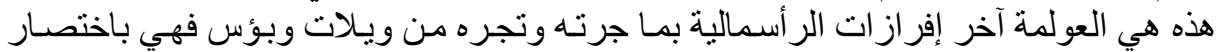

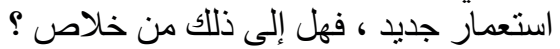

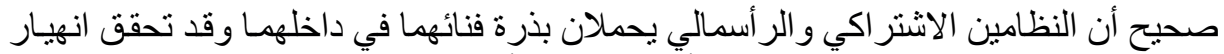

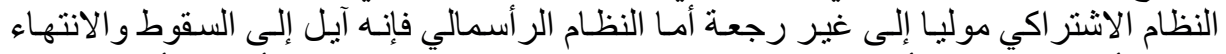

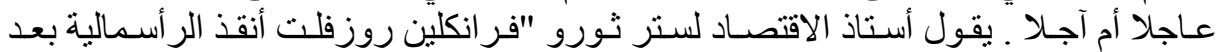

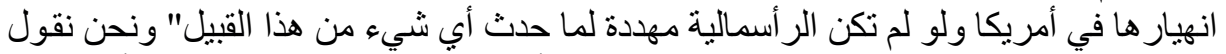

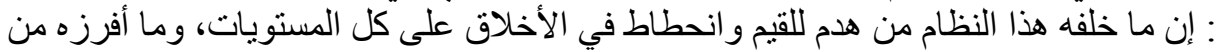

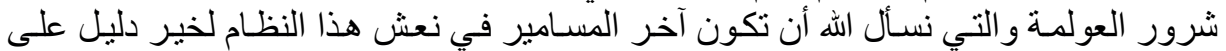

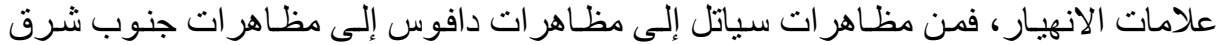

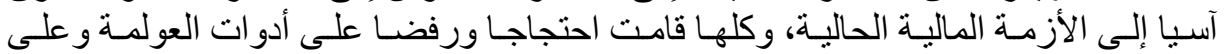

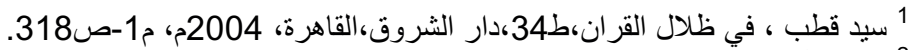

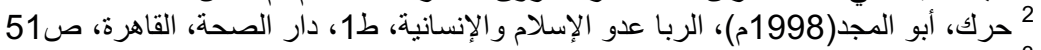

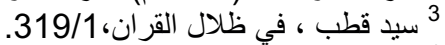
4 سليم،تنحي محمد، العولمة هي أداة الر أسمالية الحديثة للسيطرة على العالم، ص19-20. 
العولمة فهي رفض لهذا النظام ـ وهو فكرة باطلة ونظام باطل 1، قال تعالى : "إن الباطل كان

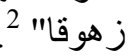

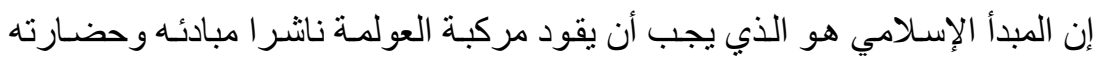

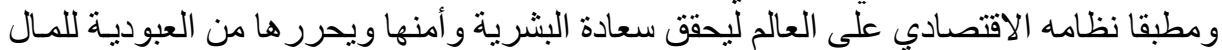

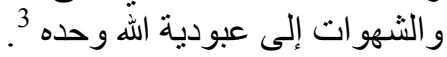
المطلب الثالث: إحداث إصلاحات ضرورية إلى داخل مؤسسة البنك الدولي:

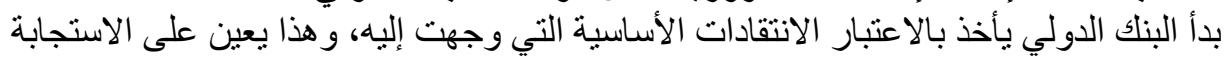

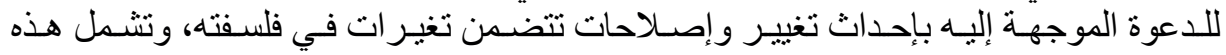

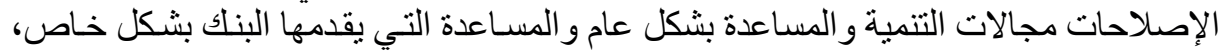

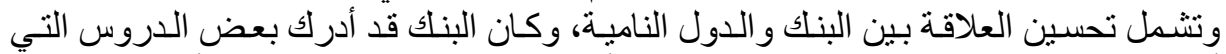

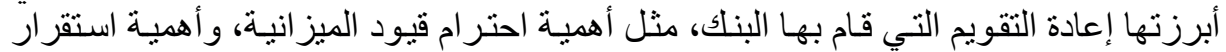

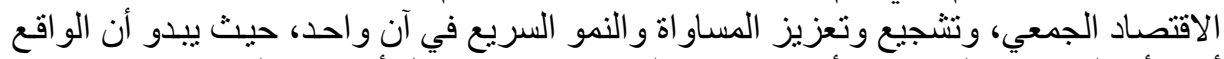

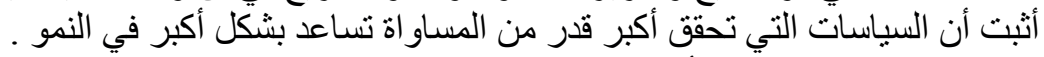

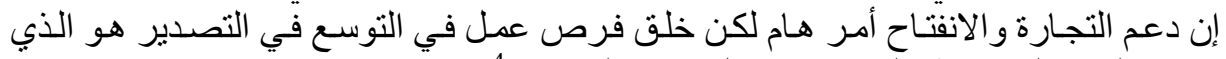

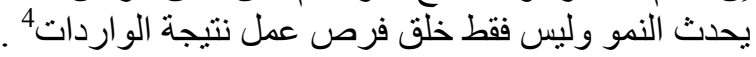

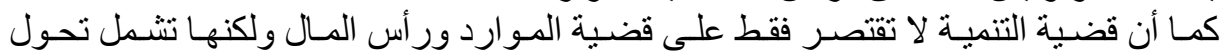

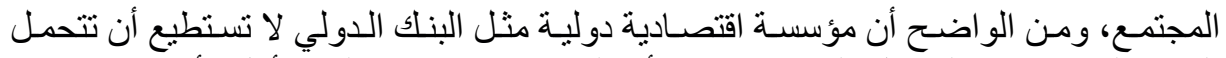

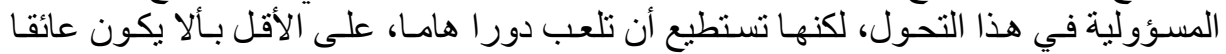

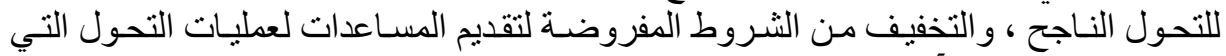
غالبا ما تكون سياسية و هذه المقترحات و إن كانت بعيدة المنال عند البعض، وضئ وضـربا من الخيـال عند البعض الآخر،

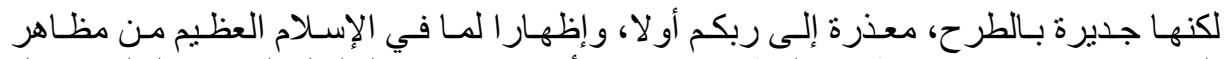

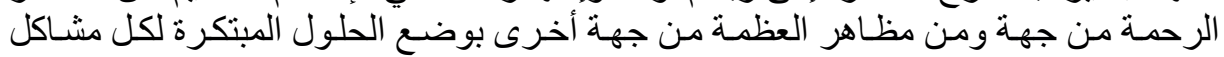

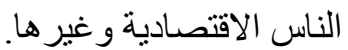

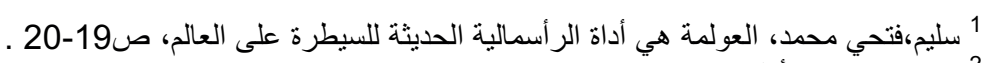

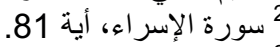

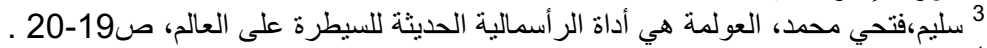

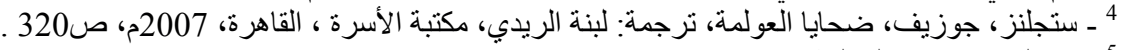

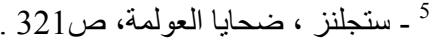




\section{الخاتمة \\ النتائج و التوصيات}

1- البنك الدولي للإنشاء و التعمير : مؤسسة مالية إعانية عالمية حاصلة على تصنيف من مرنبة AAA-

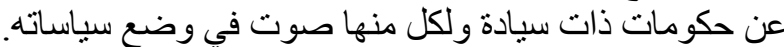

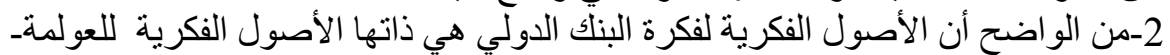

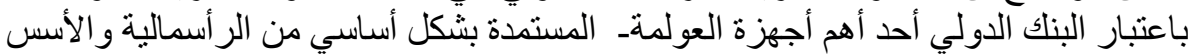
التي قامت عليها.

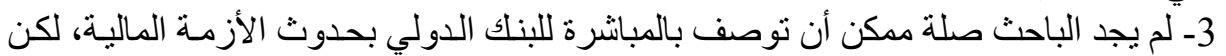

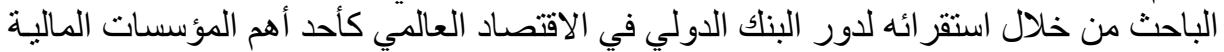

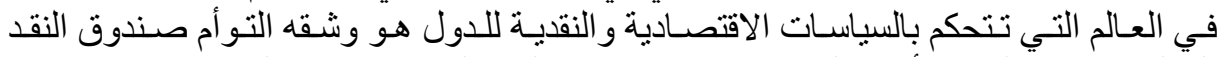
الدولي، لا حظ الباحث أن هناك صلات غير مباشرة لهذه المؤسسات في المسـاهمة في حدوث

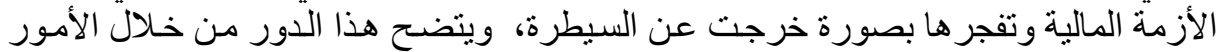
التالية.

أو لا: عدم التزام البنلك الدولي بالأهداف التي أنشئ من أجلها

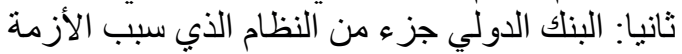

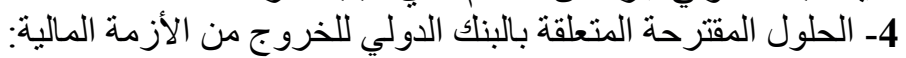

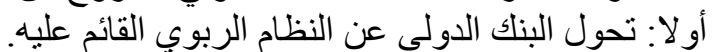

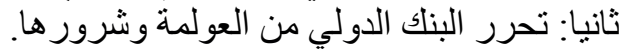
ثالثا: إحداث إصرانات تحات ضرورية داخل مؤسسة البنك الدولي.

1- - علّى الباحثين تتبع الآثار السلبية التي تتجم عن تطبيق سياسات البنك الدولي .

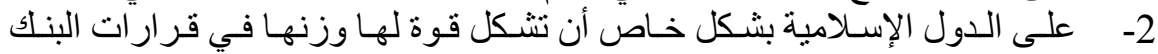

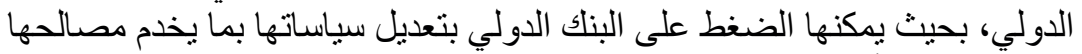

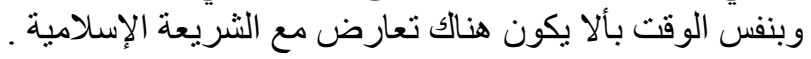


قائمة المصادر والمراجع

سيد قطب ، في ظلال القران، ط34،دار الشروق، القاهرة، 2004م. التهان.

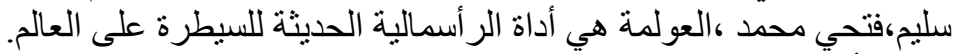

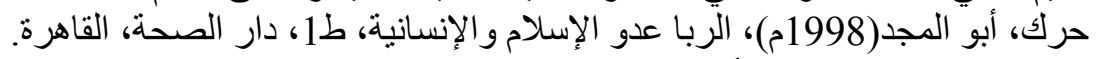

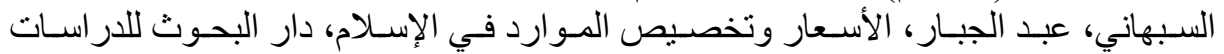

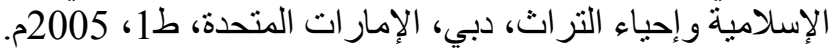

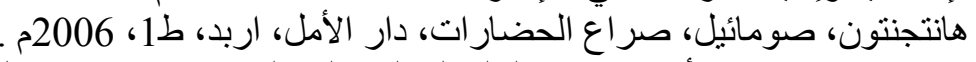

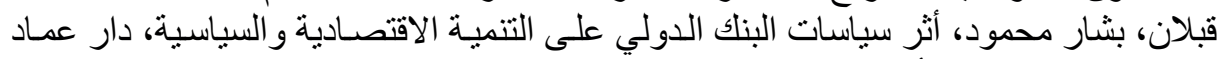

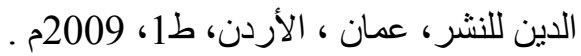

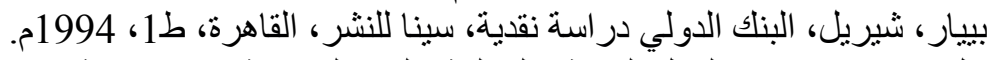

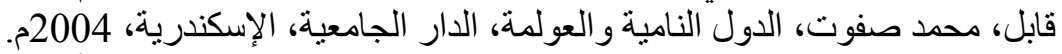

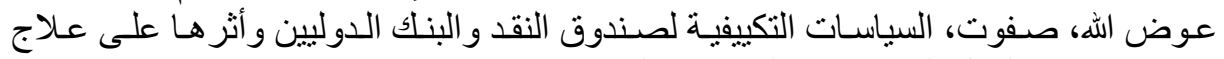

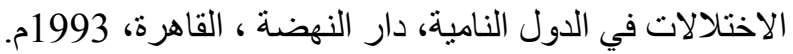

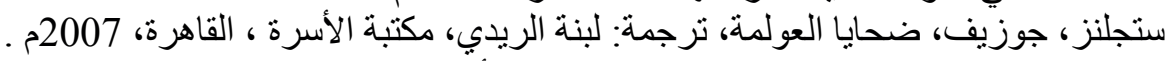

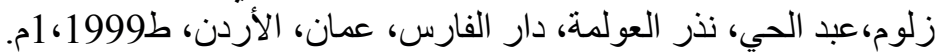

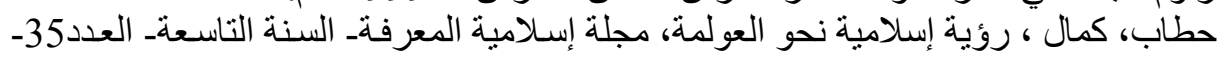

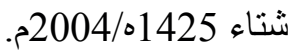

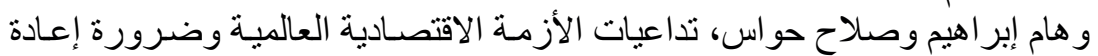

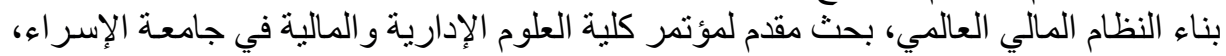
2009/4/28

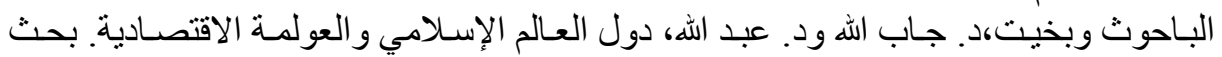

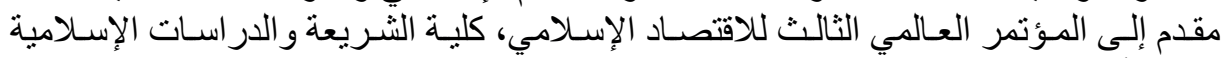

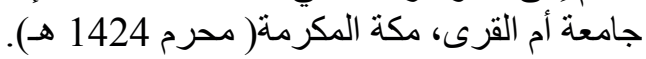

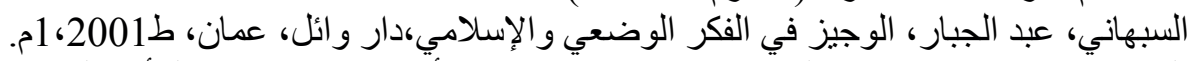

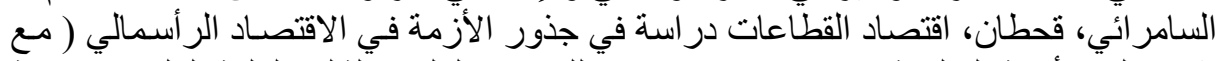

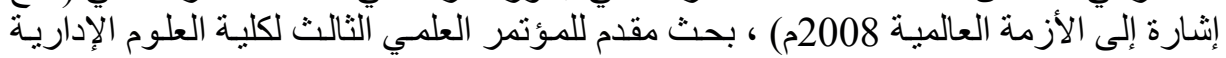

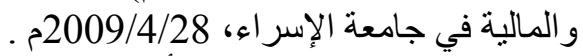

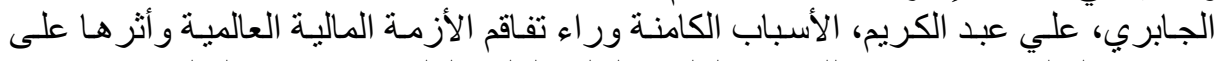

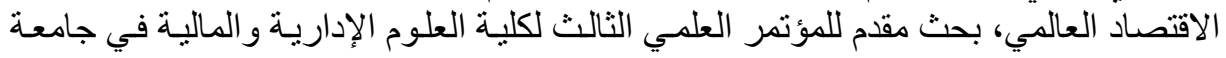

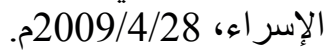
التقرير السنوي للبنك الدولي 2008م، الثؤون الخارجية في البنك الدولي، واشنطن الولايات

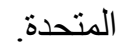

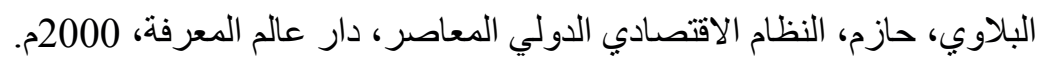

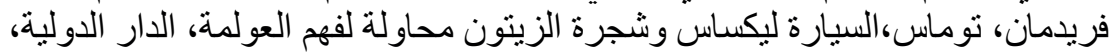

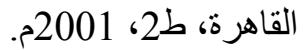


Sayed Qutb fy delal alKoran, i 34, Dar Al Shorouk, Cairo, 2004.

Salim, Mohammed Fathi, alawlamah hya adat alrasmaleah alhadethah.

Harak, Abul-Magd (1998 m), alreba adou alislam w adou alensaneah, i 1, dar alseha, alqahera.

Sabhani, Abdul-Jabbar, alasaar w tahsees almward fee alIslam, dar albhooth, Dubai, Arab Emiralates, i 1.2005 m.

Hantjnton, Samuel, sera alhadarat, dar alamal, Irbid, i 1.2006 m.

Pierre, Cheryl alBank aldawle deraseh nqdeah dar sena. Alqahera 1994.

Kapl, -Mohamad ,aldwal alnameah w alwlamah, aldar aljameah, aleskandreah, 2004.

Awad Allah, Safwat, alsyasat altkeefyah lsandoq alnaqd aldawle walbank aldawlien, dar alnahdah, alqahera , 1993.

Stjlenz, Joseph, dahaya alawlama, trjamt: lobna Reedy, alqahera, 2007.

Zaloom, Abdul Hai, ndor alawlama, Dar alfares, Amman,alurdon, i 1.1999 m.

Hattab, Kamal, roya Islameah naho alawlama, majlah Islameah almarefa, aladad al35 1425/2004.

Wham Ibrahim wa Salah, thdaiat alazmah aleqtesadiah alalameah, motmar jamiat alisra, 2009.

Alblawe, hazem. Alnedam aleqtisade aldawle almoaser. Dar alam almarefa, 2000.

Fredman, Tomas, alsyarah allexas wa shjarat alzaetoon, aldar aldawleah, alqahera,2001.

Albahot wa Bakhit, d. Jaballah d. Abdullah, dwal alalam alislamenwa lawlama alqtisadeah.al motmar alalme althaleth lleqtisad alislame, klet alSharia,lameat Umm Al Qura, Makkah (Muharram 1424).

Sabhani, Abdul-Jabbar, alwajez fe alfeker alwade ,alislame, Dar Wael, amman, i $1.2001 \mathrm{~m}$.

Samarrai, Qahtan, eqtesad alqetaat derasat fe jdor alazma, almotmar alelme althaleth, jameat alisra, 2009.

Al Jabri, Ali Abdul Karim, alasbab alkamenah wraa tfakom alazma waathroha ala aleqtisad alalme, almotmar alelme althaleth , jameat alisra, 2009.

Altqreer alsanwe llbank aldawle. Alshoon alkarejeah fe albank aldawle, washnton, alwelayat almotaheda. 
